\title{
Dietary fibre and incidence of type 2 diabetes in eight European countries: the EPIC-InterAct Study and a meta-analysis of prospective studies
}

\author{
The InterAct Consortium
}

Received: 8 August 2014 / Accepted: 16 March 2015 / Published online: 29 May 2015

(C) The Author(s) 2015. This article is published with open access at Springerlink.com

\begin{abstract}
Aims/hypothesis Intake of dietary fibre has been associated with a reduced risk of type 2 diabetes, but few European studies have been published on this. We evaluated the association between intake of dietary fibre and type 2 diabetes in the European Prospective Investigation into Cancer and Nutrition (EPIC)-InterAct study and in a meta-analysis of prospective studies.

Methods During 10.8 years of follow-up, 11,559 participants with type 2 diabetes were identified and a subcohort of 15,258 participants was selected for the case-cohort study. Countryspecific HRs were estimated using Prentice-weighted Cox proportional hazards models and were pooled using a random effects meta-analysis. Eighteen other cohort studies were identified for the meta-analysis.

Results In the EPIC-InterAct Study, dietary fibre intake was associated with a lower risk of diabetes $\left(\mathrm{HR}_{\mathrm{Q} 4}\right.$ vs Q1 $0.82 ; 95 \%$ CI $0.69,0.97$ ) after adjustment for lifestyle and dietary factors. Similar inverse associations were observed for the intake of cereal fibre and vegetable fibre, but not fruit fibre. The associations were attenuated and no longer statistically significant after adjustment for BMI. In the meta-analysis (19 cohorts), the summary RRs per $10 \mathrm{~g} /$ day increase in intake were 0.91 $(95 \%$ CI $0.87,0.96)$ for total fibre, 0.75 (95\% CI $0.65,0.86)$
\end{abstract}

The InterAct Consortium list of authors is shown in the Appendix.

Electronic supplementary material The online version of this article (doi:10.1007/s00125-015-3585-9) contains peer-reviewed but unedited supplementary material, which is available to authorised users.

The InterAct Consortium anneleen.kuijsten@wur.nl

1 c/o A. Kuijsten, Division of Human Nutrition, Wageningen University, PO Box 8129, 6700 EV Wageningen, the Netherlands for cereal fibre, $0.95(95 \% \mathrm{CI} 0.87,1.03)$ for fruit fibre and 0.93 (95\% CI $0.82,1.05)$ for vegetable fibre.

Conclusions/interpretation The overall evidence indicates that the intake of total and cereal fibre is inversely related to the risk of type 2 diabetes. The results of the EPIC-InterAct Study suggest that the association may be partially explained by body weight.

Keywords Case-cohort · Dietary fibre - EPIC-InterAct . Meta-analysis · Type 2 diabetes

\begin{abstract}
Abbreviation
EPIC European Prospective Investigation into Nutrition and Cancer
\end{abstract}

\section{Introduction}

Worldwide, there is an increasing prevalence of type 2 diabetes [1], which is likely to be driven by increasing adiposity, reduced physical activity and dietary changes. The number of people living with diabetes (mostly type 2 diabetes) worldwide has been projected to increase from 366 million in 2011 to 552 million by 2030 [1], and this trend will have important public health implications in terms of morbidity [2], mortality [2, 3] and healthcare costs [4].

The intake of dietary fibre, especially of cereal origin, has been inversely associated with risk of diabetes, as has been summarised in a meta-analysis of cohort studies by Schulze et al [5]. A higher intake of cereal fibre was associated with a $33 \%$ lower risk of diabetes compared with a low intake [5]. However, most of the studies included in this meta-analysis were from the USA, and the level and sources of fibre intake 
may differ substantially between countries. For example, in European populations $[6,7]$ total fibre intake appears to be higher than that reported in several US studies [8-10], and this may partly be explained by a higher intake of cereal fibre in Europe compared with the US [6, 8-10]. It is also not clear why cereal fibre could exert more beneficial effects on type 2 diabetes than other sources of fibre. Most cereals contain proportionally larger amounts of insoluble fibre, while most evidence from experimental studies on the benefits of fibre has been accumulated for soluble fibres [11]. The aims of this study were to evaluate the associations between total, cereal, fruit and vegetable fibre and the incidence of type 2 diabetes in a large European cohort, the European Prospective Investigation into Cancer and Nutrition (EPIC)-InterAct Study, and to summarise the existing evidence on fibre intake and type 2 diabetes in a meta-analysis of prospective studies.

\section{Methods}

\section{Study population}

The EPIC-InterAct Study is embedded in EPIC, which is a multicentre prospective cohort study designed to investigate the relationship between food habits, nutritional status, various lifestyle and environmental factors, and the incidence of cancer and other chronic diseases in ten European countries $[12,13]$. The EPIC-InterAct Study used data from eight European countries (Denmark, France, Germany, Italy, the Netherlands, Spain, Sweden and the UK) [14]. We used a nested case-cohort design, including incident cases of type 2 diabetes $(n=12,403)$ and a random subcohort $(n=16,835$, including 778 cases of incident diabetes), selected from 340,234 EPIC participants eligible for the EPIC-InterAct Study. All the participants gave written informed consent, and the study was approved by the local ethics committee at the participating centres and the Internal Review Board of the International Agency for Research on Cancer.

\section{Population for current analysis}

Of the 28,460 participants in the EPIC-InterAct nested casecohort sample, we excluded participants with prevalent diabetes $(n=548)$, missing information on reported diabetes status $(n=129)$, post-censoring diabetes $(n=4)$, extreme energy intake (in the top $1 \%$ and bottom $1 \%$ of the distribution of the ratio of reported energy intake over estimated energy requirement, assessed by basal metabolic rate; $n=736$ ), and participants with missing values for educational level $(n=479)$, physical activity $(n=180)$, smoking status $(n=131)$ and BMI $(n=165)$. This left a final sample of 11,559 cases and 15,258 subcohort participants ( 729 of the diabetes cases being from the subcohort), for the current analysis (a total of 26,088 participants). No differences were observed in baseline characteristics between the included and excluded participants.

\section{Incidence of diabetes}

Incident cases of diabetes were identified on the basis of selfreporting, a linkage to primary care registers or secondary care registers, medication use, hospital admissions and mortality data [14]. The identified cases were verified with further evidence, including individual medical record reviews. Cases in Denmark and Sweden were not ascertained by self-reporting but were identified via local and national diabetes and pharmaceutical registers. Follow-up was censored at the date of diagnosis, 31 December 2007 or the date of death, whichever occurred first. In total, 11,559 verified incident cases were identified during follow-up and were eligible for the current analysis.

\section{Fibre intake and other dietary variables}

Dietary intake over the previous 12 months before recruitment was assessed by country-specific or centre-specific dietary assessment methods (food frequency questionnaires and dietary histories) that were developed and validated locally [12, $15,16]$. The food intake data were converted to nutrient intake using the European Nutrient Database [17]. The method for estimating total dietary fibre intake has previously been described [18]. In brief, the gravimetric method of the Association of Official Analytical Chemists [19] was used for estimating the total dietary fibre (which includes soluble and insoluble forms of non-starch polysaccharides and resistant starch as fibre) in all countries except the UK, where total dietary fibre was estimated by the Englyst method (which includes non-starch polysaccharides but not lignin or resistant starch). For the present study, we used measurements of total dietary fibre and fibre from cereals, fruits and vegetables, which are the main fibre sources in all eight countries.

\section{Lifestyle variables}

Baseline information on lifestyle factors was obtained from questionnaires. Weight, height and waist circumference were measured by trained staff during standardised health checks at baseline in all centres, except for a proportion of participants in Oxford (UK) and France, for whom self-reported data were obtained, and Umeå (Sweden), where waist circumference was not measured. Physical activity was assessed by questionnaire and was classified according to the Cambridge Physical Activity Index [20, 21]. 


\section{Statistical analysis}

We examined the association by country between quarters of the distribution of fibre intake in the subcohort (hereafter referred to as quartiles) adjusted for energy using the residual method [22] and the incidence of type 2 diabetes using Cox proportional hazard models modified for the case-cohort design according to the Prentice method [23]. The underlying time metric was age. In order to adjust for time to follow-up, the age at recruitment ( 1 year categories) was included as a stratum variable. Country-specific HRs and $95 \%$ CIs were pooled using random effects meta-analyses [24]. Betweencountry heterogeneity was assessed using the $I^{2}$ statistic, i.e. the percentage of variation in the HR that was attributable to between-country heterogeneity [25]. The significance of linear trends across quartiles of total and different sources of fibre was tested by assigning the median value of the quartile to each participant and modelling these values as a continuous variable.

Confounders were assessed at baseline and those included in the models were age and sex (model 1), lifestyle and classical diabetes risk factors (model 2), dietary factors (model 3 ) and BMI (model 4). Each model was additionally adjusted for the preceding model. Lifestyle and classical diabetes risk factors included smoking status (never smoker, former smoker or current smoker), physical activity level based on an index of activity (inactive, moderately inactive, moderately active or active) $[20,21]$, education level (low, secondary or high) and alcohol intake $(0=$ non-drinker, $1=0-12 / 0-6 \mathrm{~g} /$ day for men and women, respectively, $2=12-24 / 6-12 \mathrm{~g} /$ day or $3 \geq$ $24 / 12 \mathrm{~g} /$ day). Dietary factors included the total energy intake and the energy-adjusted intake of carbohydrates, magnesium, vitamin $\mathrm{B}_{1}$ and saturated fatty acids (continuous). The final model also adjusted for BMI (continuous). All models for subgroups of fibre were mutually adjusted for each other. Variables not included in the multivariable models because they did not change the risk estimates are listed in the electronic supplementary material (ESM) methods. A number of stratified and sensitivity analyses were conducted, and these are described in the ESM methods.

Analyses were conducted in SAS version 9.2 (SAS Institute, Cary, NC, USA), except for the meta-analyses, which were conducted in Stata 11.0 (Stata, College Station, TX, USA). A two-sided $p$ value $\leq 0.05$ was considered statistically significant for all analyses.

\section{Meta-analysis}

We searched PubMed up to and including 24 January 2014 for prospective studies of fibre intake and risk of type 2 diabetes using the keywords 'fiber', 'fibre' and 'diabetes'. Eighteen cohorts (20 publications) $[5-10,26-39]$ in addition to the present study were included in the analyses. More details of the study selection and methods can be found in the ESM methods. Random effects models were used to calculate summary RRs comparing the highest with the lowest category of fibre intake and for the dose-response analysis [24]. Doseresponse analyses were conducted using the method described by Greenland and Longnecker [40]. Non-linear doseresponse analyses were conducted using fractional polynomial models [41], and a likelihood ratio test was used to test for nonlinearity [41]. We quantified the extent of heterogeneity by using $I^{2}$ [25]. We tested for small-study bias using Egger's test [42] and by inspecting the funnel plots. All statistical analyses for the meta-analysis were conducted using the statistical package STATA 11.0.

\section{Results}

\section{The EPIC-InterAct Study}

The study population consisted of 26,088 participants. The average age at baseline in the subcohort $(n=15,258)$ was $52.4 \pm 9.1$ years. Participants who had a high fibre intake ( $>26.4 \mathrm{~g} /$ day) were less likely to smoke, drank little alcohol and were more physically active than those with a low fibre intake $(<18.9 \mathrm{~g} /$ day; Table 1). The proportion of men was higher in the lowest quartile of fibre intake $(50 \%$ men) than in the next three quartiles (31-35\%). Although the mean BMI was slightly higher in participants with a higher fibre intake (Table 1), this may have been confounded by country as fibre intake was positively associated with BMI only in Spain and the Netherlands, was not associated with BMI in Italy, and was inversely associated with BMI in the remaining countries (ESM Table 1).

The mean \pm SD fibre intake in the subcohort was $22.9 \pm$ $6.2 \mathrm{~g} /$ day (ranging from $19.9 \mathrm{~g} /$ day in Sweden to $25.2 \mathrm{~g} /$ day in Denmark; data not shown). Cereals were the main source of fibre (38\%) in all countries except France, where vegetables were the main source of fibre. Of the cereal fibres, $81 \%$ originated from bread (ranging from $56 \%$ in the UK to $90 \%$ in Germany), $8 \%$ from pasta and rice (with the highest amounts in Italy [23\%] and France [16\%]) and 7\% from breakfast cereals (with the highest amount in the UK [28\%]). Other sources of fibre in consecutive order were fibre from fruits and nuts $(20 \%)$, vegetables $(18 \%)$, potatoes and tubers $(9 \%)$ and legumes (5\%). Cereal, fruit and vegetable fibres together accounted for around $75 \%$ of total fibre in all countries (data not shown).

During a median of 10.8 years of follow-up, we ascertained 11,559 incident cases of type 2 diabetes. After adjusting for lifestyle factors and dietary factors, total fibre intake was associated with a lower risk of diabetes $\left(\mathrm{HR}_{\mathrm{Q} 4}\right.$ vs Q1 $0.82 ; 95 \%$ CI 0.69, 0.97; $p$ for trend $=0.02$; Table 2). When evaluating the fibre sources, the highest vs the lowest quartile of intake of 
Table 1 Study characteristics (mean $\pm \mathrm{SD}$, unless otherwise specified) in a random subcohort from the EPIC-InterAct study stratified by quartiles of energy-adjusted total fibre intake $(n=15,258)$

\begin{tabular}{|c|c|c|c|c|c|}
\hline Variable & $n$ & Q1 & Q2 & Q3 & Q4 \\
\hline Cutoffs (g/day) & & $<18.9$ & $18.9-<22.4$ & $22.4-26.4$ & $>26.4$ \\
\hline Median (g/day) & & 16.3 & 20.7 & 24.2 & 29.7 \\
\hline Age (years) & 15,258 & $52.0 \pm 9.4$ & $52.2 \pm 9.1$ & $52.6 \pm 9.0$ & $52.8 \pm 8.7$ \\
\hline Men $(\%)$ & 15,258 & 50 & 35 & 31 & 35 \\
\hline Follow-up (years) & 15,258 & $12.0 \pm 2.5$ & $12.0 \pm 2.3$ & $11.9 \pm 2.4$ & $12.0 \pm 2.2$ \\
\hline BMI $\left(\mathrm{kg} / \mathrm{m}^{2}\right)$ & 15,258 & $25.8 \pm 4.0$ & $26.0 \pm 4.2$ & $26.2 \pm 4.2$ & $26.2 \pm 4.3$ \\
\hline BMI (\% obese) & 15,258 & 14 & 16 & 17 & 16 \\
\hline \multicolumn{6}{|l|}{ Waist circumference $(\mathrm{cm})$} \\
\hline Men & 5,282 & $94.8 \pm 10.2$ & $94.9 \pm 9.9$ & $95.9 \pm 9.6$ & $95.1 \pm 9.8$ \\
\hline Women & 8,963 & $80.1 \pm 11.4$ & $81.0 \pm 10.9$ & $81.7 \pm 11.0$ & $81.9 \pm 11.3$ \\
\hline First-degree relatives with diabetes ( $\%$ yes) ${ }^{\mathrm{a}}$ & 7,615 & 17 & 19 & 21 & 19 \\
\hline Smoking ( $\%$ current $)$ & 15,258 & 37 & 26 & 23 & 18 \\
\hline Hypertension (\% yes) & 14,930 & 18 & 19 & 20 & 19 \\
\hline Hyperlipidaemia (\% yes) & 11,389 & 18 & 19 & 19 & 19 \\
\hline Myocardial infarction (\% yes) & 15,007 & 1.4 & 1.3 & 1.5 & 1.4 \\
\hline Angina (\% yes) & 10,078 & 1.7 & 1.8 & 2.3 & 2.4 \\
\hline Stroke (\% yes) & 14,036 & 0.9 & 0.9 & 0.8 & 0.8 \\
\hline Educational level (\% high) & 15,258 & 21 & 21 & 20 & 21 \\
\hline Physical activity (\% inactive) & 15,258 & 25 & 24 & 23 & 22 \\
\hline Postmenopausal women (\%) & 9,484 & 44 & 46 & 47 & 51 \\
\hline \multicolumn{6}{|l|}{ Dietary factors } \\
\hline Energy (kJ/day) & 15,258 & $9,320 \pm 2,834$ & $8,579 \pm 2,562$ & $8,629 \pm 2,516$ & $9,286 \pm 2,617$ \\
\hline Fat $(\mathrm{en} \%)$ & 15,258 & 36.7 & 35.4 & 34.3 & 32.7 \\
\hline Saturated fatty acids & & 14.8 & 13.6 & 12.8 & 11.7 \\
\hline Monounsaturated fatty acids & & 13.8 & 13.5 & 13.0 & 12.4 \\
\hline Polyunsaturated fatty acid & & 5.4 & 5.6 & 5.7 & 5.7 \\
\hline Protein $(\mathrm{en} \%)$ & 15,258 & 16.5 & 17.0 & 17.3 & 17.4 \\
\hline Carbohydrates (en\%) & 15,258 & 40.6 & 43.35 & 45.1 & 47.0 \\
\hline Starch & & 21.6 & 23.7 & 24.5 & 25.4 \\
\hline Sugars & & 18.4 & 19.1 & 20.0 & 20.9 \\
\hline Magnesium (mg/day) & 15,258 & $313 \pm 64$ & $337 \pm 59$ & $362 \pm 61$ & $398 \pm 65$ \\
\hline Cholesterol (mg/day) & 15,258 & $373 \pm 125$ & $352 \pm 105$ & $337 \pm 104$ & $314 \pm 113$ \\
\hline Vitamin $B_{1}$ (mg/day) & 15,258 & $1.2 \pm 0.3$ & $1.3 \pm 0.3$ & $1.4 \pm 0.3$ & $1.5 \pm 0.4$ \\
\hline$\beta$-Carotene (mg/day) & 15,258 & $1.9 \pm 1.3$ & $2.6 \pm 1.6$ & $3.1 \pm 1.9$ & $4.4 \pm 3.8$ \\
\hline Vitamin C (mg/day) & 15,258 & $88 \pm 44$ & $111 \pm 45$ & $131 \pm 52$ & $167 \pm 83$ \\
\hline Vitamin E (mg/day) & 15,258 & $10.1 \pm 4.1$ & $11.5 \pm 3.9$ & $12.0 \pm 4.1$ & $13.1 \pm 4.9$ \\
\hline GI (not energy adjusted) & 15,258 & $56.6 \pm 4.1$ & $55.9 \pm 3.8$ & $55.9 \pm 3.8$ & $55.8 \pm 3.9$ \\
\hline GL (not energy adjusted) & 15,258 & $128 \pm 47$ & $124 \pm 44$ & $130 \pm 43$ & $145 \pm 47$ \\
\hline Alcohol (g/day) median (P10; P90), not energy adjusted & 15,258 & $12(0 ; 58)$ & $7(0 ; 37)$ & $5(0 ; 31)$ & $4(0 ; 30)$ \\
\hline Alcohol (\% non-drinkers) & 15,258 & 19 & 26 & 29 & 31 \\
\hline
\end{tabular}

${ }^{\text {a }}$ Family history of diabetes was not ascertained in Italy, Spain, Oxford and Heidelberg (excluded from this summary)

en $\%$, percentage of total energy intake; GI, glycaemic index; GL, glycaemic load; P10, 10th percentile; P90, 90th percentile

cereal fibre (HR 0.81; 95\% CI 0.70, 0.93; $p$ for trend $<0.01$ ) and vegetable fibre (HR $0.84 ; 95 \% \mathrm{CI} 0.74,0.96 ; p$ for trend $<0.01$ ) were inversely associated with the risk of diabetes, but fruit fibre (HR 0.98; 95\% CI 0.89, 1.08; $p$ for trend $=0.74$ ) was not associated with risk of diabetes. However, when the analyses were additionally adjusted for BMI, the inverse associations were attenuated and no longer statistically significant. When comparing the highest with the lowest quartile, the 
Table 2 HRs $(95 \%$ CI) for the associations between quartiles of dietary fibre and incident type 2 diabetes in the EPIC-InterAct Study $(n=26,088)$

\begin{tabular}{|c|c|c|c|c|c|}
\hline Variable & Q1 & Q2 & Q3 & Q4 & $p$ \\
\hline Total fibre, g/day (median) & $<18.9(16.3)$ & $18.9-22.4(20.7)$ & $22.4-26.4(24.2)$ & $>26.4(29.7)$ & \\
\hline Model 1 'age, sex' & 1.00 & $0.91(0.82,1.02)$ & $0.90(0.79,1.02)$ & $0.93(0.78,1.11)$ & 0.08 \\
\hline Model 2 'lifestyle' & 1.00 & $0.92(0.82,1.04)$ & $0.91(0.81,1.02)$ & $0.84(0.69,1.02)$ & 0.07 \\
\hline Model 3 'lifestyle and diet' & 1.00 & $0.92(0.83,1.02)$ & $0.91(0.82,1.01)$ & $0.82(0.69,0.97)$ & 0.02 \\
\hline Model 4 'lifestyle, diet and BMI' & 1.00 & $0.93(0.84,1.03)$ & $0.98(0.89,1.08)$ & $0.91(0.81,1.03)$ & 0.28 \\
\hline Cereal fibre, g/day (median) & $<5.7(4.3)$ & $5.7-7.9(6.8)$ & $7.9-10.9(9.3)$ & $>10.9(13.7)$ & \\
\hline Model 1 'age, sex' & 1.00 & $0.89(0.80,0.99)$ & $0.88(0.77,1.00)$ & $0.85(0.72,1.00)$ & 0.03 \\
\hline Model 2 'lifestyle' & 1.00 & $0.89(0.80,0.98)$ & $0.89(0.80,0.99)$ & $0.82(0.72,0.93)$ & $<0.01$ \\
\hline Model 3 'lifestyle and diet' & 1.00 & $0.90(0.80,1.00)$ & $0.91(0.82,1.00)$ & $0.81(0.70,0.93)$ & $<0.01$ \\
\hline Model 4 'lifestyle, diet, and BMI' & 1.00 & $0.90(0.80,1.02)$ & $1.00(0.90,1.10)$ & $0.95(0.83,1.08)$ & 0.49 \\
\hline Fruit fibre, g/day (median) & $<2.3(1.4)$ & $2.3-4.0(3.1)$ & $4.0-6.6(5.1)$ & $>6.3(8.4)$ & \\
\hline Model 1 'age, sex' & 1.00 & $0.88(0.82,0.95)$ & $0.91(0.83,1.00)$ & $0.89(0.81,0.98)$ & 0.17 \\
\hline Model 2 'lifestyle' & 1.00 & $0.91(0.84,0.98)$ & $0.96(0.88,1.04)$ & $0.93(0.85,1.01)$ & 0.41 \\
\hline Model 3 'lifestyle and diet' & 1.00 & $0.93(0.86,1.00)$ & $0.98(0.90,1.06)$ & $0.98(0.89,1.08)$ & 0.74 \\
\hline Model 4 'lifestyle, diet, and BMI' & 1.00 & $0.91(0.82,1.00)$ & $0.93(0.84,1.03)$ & $0.96(0.83,1.10)$ & 0.76 \\
\hline Vegetable fibre, g/day (median) & $<2.4(1.6)$ & $2.4-3.6(3.0)$ & $3.6-5.3(4.4)$ & $>5.3(6.9)$ & \\
\hline Model 1 'age, sex' & 1.00 & $0.95(0.88,1.02)$ & $0.87(0.76,0.98)$ & $0.93(0.78,1.11)$ & 0.57 \\
\hline Model 2 'lifestyle' & 1.00 & $0.98(0.91,1.06)$ & $0.91(0.81,1.03)$ & $0.98(0.85,1.14)$ & 0.92 \\
\hline Model 3 'lifestyle and diet' & 1.00 & $0.94(0.87,1.01)$ & $0.82(0.71,0.94)$ & $0.84(0.74,0.96)$ & $<0.01$ \\
\hline Model 4 'lifestyle, diet, and BMI' & 1.00 & $0.91(0.84,0.99)$ & $0.83(0.71,0.97)$ & $0.93(0.84,1.03)$ & 0.11 \\
\hline
\end{tabular}

Model 1 was adjusted for age and sex

Model 2 was additionally adjusted for lifestyle factors: smoking status, physical activity, education level and sex-specific alcohol categories

Model 3 was additionally adjusted for dietary factors: energy and energy-adjusted carbohydrates, magnesium, vitamin $\mathrm{B}_{1}$ and saturated fatty acids

Model 4 was additionally adjusted for BMI

All models for types of fibre were mutually adjusted

HRs were $0.91(95 \%$ CI $0.81,1.03$; $p$ for trend $=0.28)$ for total fibre, $0.95(95 \%$ CI $0.83,1.08 ; p$ for trend $=0.49)$ for cereal fibre, $0.96(95 \%$ CI $0.83,1.10$; $p$ for trend $=0.76)$ for fruit fibre and $0.93(95 \%$ CI $0.84,1.03 ; p$ for trend $=0.11)$ for vegetable fibre. Adjustment for BMI explained $50 \%$ of the association between total fibre and type 2 diabetes. We did not observe substantial between-country heterogeneity for total fibre or sources of fibre $\left(I^{2}=2.6 \%, 7.0 \%, 34.3 \%\right.$ and $0 \%$ for total, cereal, fruit and vegetable fibre, respectively; Fig. 1). The association between dietary fibre and type 2 diabetes was not modified by sex, BMI, physical activity, smoking, magnesium intake, vitamin $\mathrm{B}_{1}$ intake, glycaemic index or glycaemic load (all $p>0.05$ ). The results were not materially altered in several sensitivity analyses (see ESM results).

\section{Meta-analysis}

Eighteen independent cohorts (20 publications) [5-10, 26-39] in addition to the EPIC-InterAct study were included in the meta-analysis, with a total of 617,968 participants and 41,066 incident cases of type 2 diabetes (Table 3, ESM Fig. 1). The study characteristics of the cohorts are provided in Table 3. Of the 19 cohort studies, eight were conducted in the USA, five in Europe, three in Australia and three in Asia.

Total fibre Sixteen studies [6-10, 26, 28-30, 32-34, 36-39] in addition to the EPIC-InterAct Study were included in the analysis of total fibre and type 2 diabetes (36,578 cases among 572, 665 participants). Two of the studies $[37,38]$ were only included in the analysis of the highest vs the lowest intake. The summary RR comparing the highest vs the lowest intake was 0.85 $\left(95 \%\right.$ CI $\left.0.77,0.94 ; I^{2} 61.0 \%, p_{\text {heterogeneity }}=0.002, n=13\right)(\mathrm{ESM}$ Fig. 2a), and in the dose-response analysis the summary RR per $10 \mathrm{~g} /$ day was 0.91 (95\% CI $0.87,0.96 ; I^{2} 29.4 \%, p_{\text {heterogeneity }}=$ $0.14, n=15$ ) (Fig. 2a). There was no evidence of non-linearity, with $p_{\text {non-linearity }}=0.37$ (Fig. 2b, ESM Table 2).

Cereal fibre Twelve studies (13 publications) [6, 8-10, 26-33, 35] in addition to the EPIC-InterAct Study were included in the analysis (30,224 cases and 455,563 participants). One of the studies [32] was only included in the analysis of the highest vs the lowest intake. The summary RR for the highest vs the lowest cereal fibre intake was 0.77 (95\% CI 0.68, 0.87; $\left.I^{2} 77.7 \%, p_{\text {heterogeneity }}<0.0001, n=12\right)$ (ESM Fig. 2b) and per $10 \mathrm{~g} /$ day was $0.75\left(95 \%\right.$ CI $0.65,0.86 ; I^{2}=75.1 \%, p_{\text {heterogeneity }}$ 


$\begin{array}{lll}\text { Country } & \\ \text { Total fibre } & \\ \text { France } \\ \text { Italy } \\ \text { Spain } \\ \text { UK } \\ \text { Netherlands } \\ \text { Germany } \\ \text { Sweden } \\ \text { Denmark } \\ \text { Subtotal }\left(I^{2}=2.6 \%, p=0.410\right) \\ \text { Cereal fibre }\end{array}$

Fig. 1 Association between cereal fibre, fruit fibre and vegetable fibre consumption and risk of type 2 diabetes in the EPIC-InterAct study $(n=$ $26,088)$. Country-specific $\mathrm{HR}_{\mathrm{Q} 4}$ vs $\mathrm{Q} 1(95 \% \mathrm{CIs})$ were pooled using random effects meta-analysis. HRs were adjusted for sex, smoking status, physical activity, education level, sex-specific alcohol categories, energy, energy-adjusted carbohydrate, magnesium intake, vitamin $B_{1}$ intake, saturated fatty acids and BMI. The $x$-axis is on a log scale

$<0.0001, n=12$ ) (Fig. 2c). There was evidence of nonlinearity $\left(p_{\text {non-linearity }}=0.004\right)$, with a steeper reduction in risk at higher levels of fibre intake (Fig. 2d, ESM Table 2).

Fruit fibre Ten studies [6, 8-10, 26, 28-30, 33, 36] in addition to the EPIC-InterAct Study were included in the analysis (25,715 cases among 408,416 participants). The summary RR for the highest vs the lowest intake of fruit fibre was 0.95 $\left(95 \%\right.$ CI $\left.0.88,1.01 ; I^{2} 16.9 \%, p_{\text {heterogeneity }}=0.29, n=10\right)$ (ESM Fig. 2c) and per $10 \mathrm{~g} /$ day was 0.95 (95\% CI 0.87 , $1.03, I^{2} 31.1 \%, p_{\text {heterogeneity }}=0.15, n=11$ ) (Fig. 3a). There was a suggestive non-linear association between fruit fibre and risk of type 2 diabetes ( $p_{\text {non-linearity }}=0.04$ ), with a slightly steeper curve when increasing intake from low levels, but the association was very weak (Fig. 3b, ESM Table 2).

Vegetable fibre Ten studies [6, 8-10, 26, 29, 30, 32, 33, 36] in addition to the EPIC-InterAct Study were included in the analysis $(24,428$ cases among 399,593 participants). One of the studies [32] was only included in the analysis of the highest vs the lowest intake. The summary RR for the highest vs the lowest intake was $0.96\left(95 \%\right.$ CI $0.86,1.07 ; I^{2} 48.3 \%, p_{\text {heterogeneity }}=$ $0.04, n=10)$ (ESM Fig. 2d) and per $10 \mathrm{~g} /$ day was $0.93(95 \%$ CI $0.82,1.05 ; I^{2}=43.5 \%, p_{\text {heterogeneity }}=0.07, n=10$ ) (Fig. $3 \mathrm{c}$ ). There was evidence of a non-linear association between vegetable fibre and risk of type 2 diabetes, $\left(p_{\text {non-linearity }}<0.0001\right)$, with an inverse association restricted to a very high intake (12-14 g/ day) (Fig. 3d, ESM Table 2).

Soluble and insoluble fibre Only three studies [5, 6, 10] investigated the intake of soluble and insoluble fibre and risk of diabetes (2,141 cases among 65,373 participants). The summary RR for the highest vs the lowest intake was 0.85 $\left(95 \%\right.$ CI $\left.0.72,1.01 ; I^{2}=41.9 \%, p_{\text {heterogeneity }}=0.18\right)$ for soluble fibre and 0.75 (95\% CI $\left.0.57,0.97 ; I^{2}=0 \%, p_{\text {heterogeneity }}=0.44\right)$ (ESM Fig. 3a, b) for insoluble fibre. In the dose-response analysis, the summary RR per $10 \mathrm{~g} /$ day was $0.70(95 \% \mathrm{CI}$ $\left.0.47,1.04 ; I^{2}=0 \%, p_{\text {heterogeneity }}=0.50\right)$ for soluble fibre and $0.73\left(95 \%\right.$ CI $\left.0.62,0.86 ; I^{2}=0 \%, p_{\text {heterogeneity }}=0.46\right)$ for insoluble fibre (ESM Fig. 3c, d).

Subgroup, sensitivity analyses and publication bias The results were in general consistent across the strata in the subgroup (ESM Tables 3 and 4) and sensitivity analyses (ESM results). Most of the studies adjusted for BMI, and the results persisted among studies that adjusted for BMI (ESM Tables 3 and 4). In the analysis of cereal fibre there was a suggestion of small-study bias with Egger's test $(p=0.08)$ and asymmetry in the funnel plot suggesting that smaller studies with positive associations were missing (ESM Fig. 4). When restricting the analysis to four studies [10, 28, 31, 33] and the EPIC-InterAct study that had $\geq 1,000$ cases, Egger's test was no longer significant $(p=0.25)$, but the inverse association was similar to the overall analysis (summary RR $0.76 ; 95 \%$ CI 0.63, 0.92; $\left.I^{2}=81.0 \%, p_{\text {heterogeneity }}<0.0001\right)$. There was no evidence of publication bias for total fibre, fruit fibre or vegetable fibre ( $p=0.16, p=0.73$ and $p=0.74$, respectively).

\section{Discussion}

The EPIC-InterAct study showed that a high intake of total fibre compared with a low intake was associated with an $18 \%$ lower risk of incident type 2 diabetes when adjusted for lifestyle and dietary factors. This was mainly driven by the intake of cereal fibre and vegetable fibre, and not by fruit fibre. When 


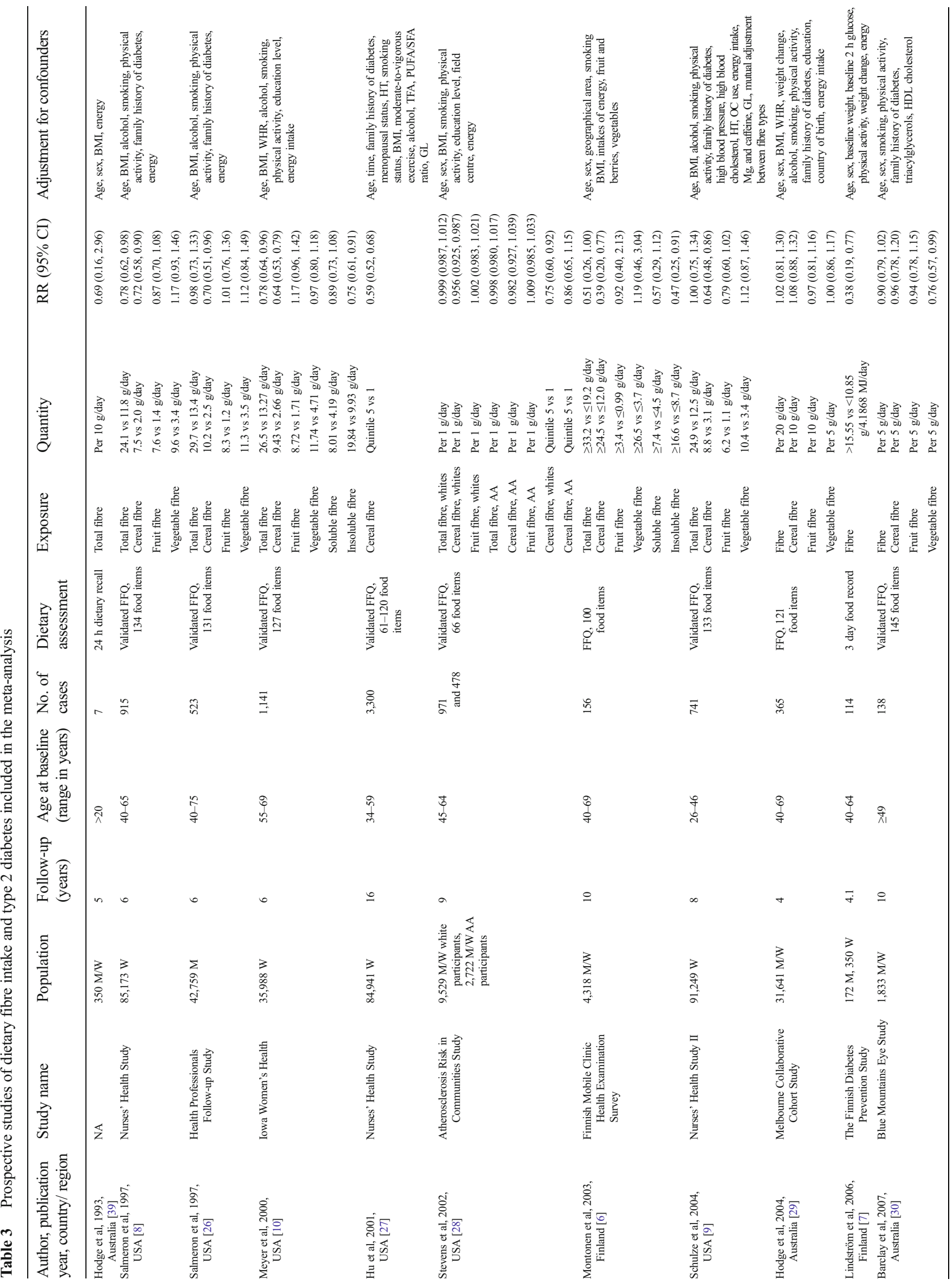




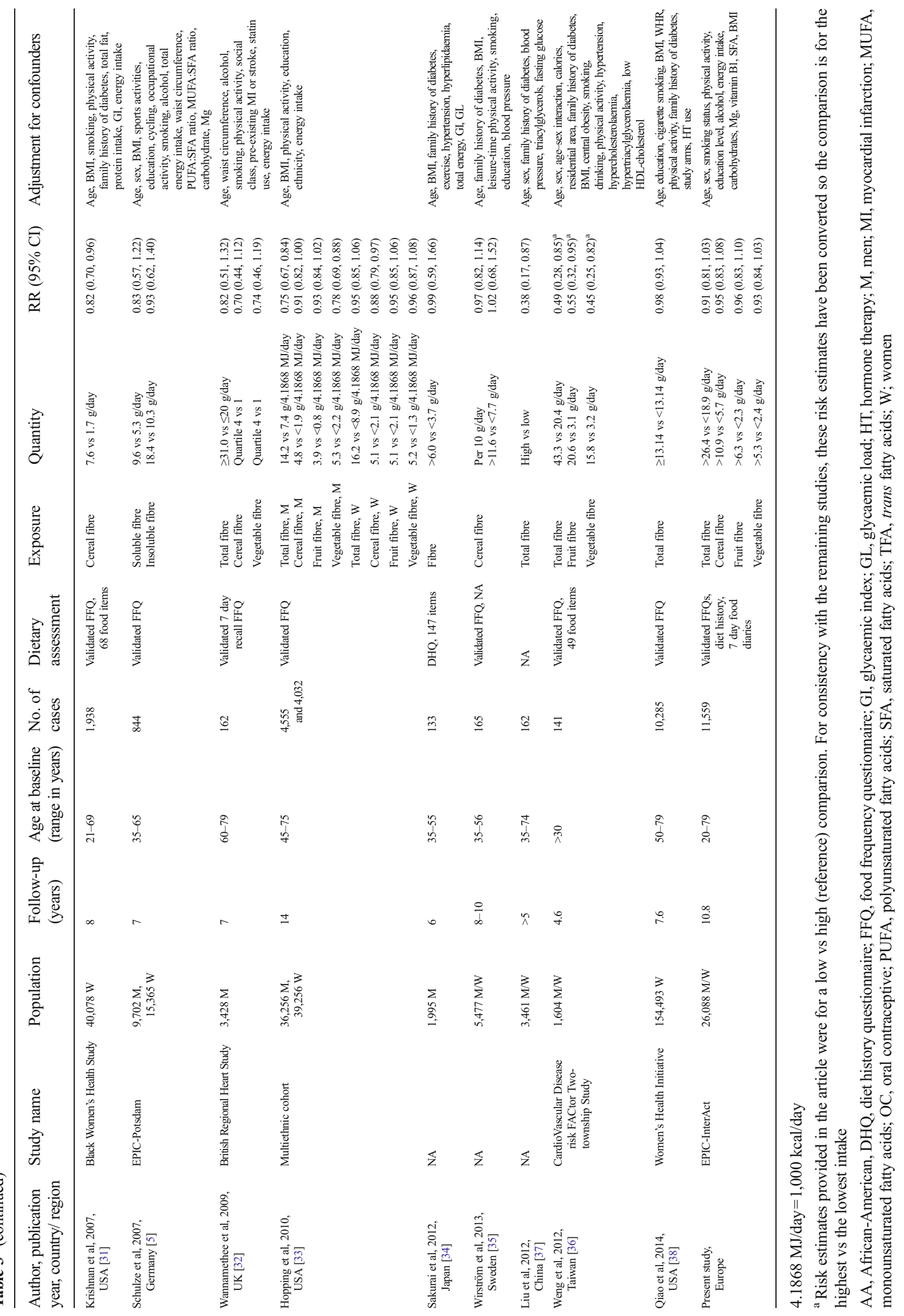


a

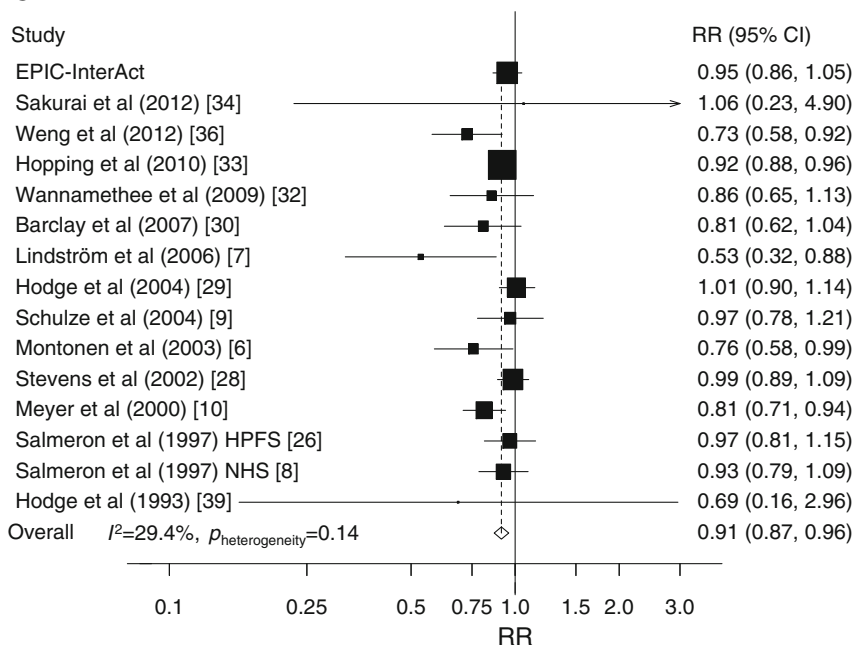

b

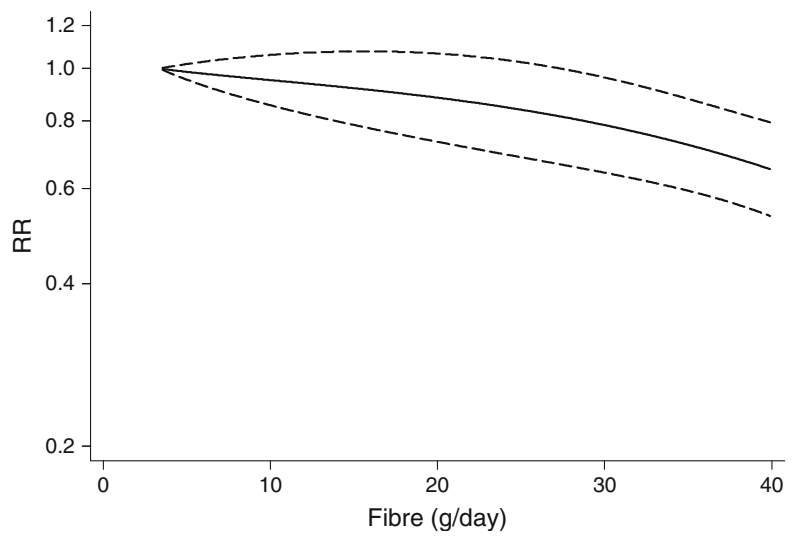

Fig. 2 Dietary total fibre $(\mathbf{a}, \mathbf{b})$ and cereal fibre $(\mathbf{c}, \mathbf{d})$ and type 2 diabetes, linear dose-response meta-analyses per $10 \mathrm{~g} /$ day $(\mathbf{a}, \mathbf{c})$ and non-linear dose-response meta-analyses (b, d). In (a) and (c), the RR of each study is represented by a square, and the size of the square represents the weight of each study to the overall estimate. The $95 \%$ CIs are represented by

the results were adjusted for BMI, total fibre and cereal and vegetable fibre were not significantly associated with risk of type 2 diabetes. However, the findings from our updated metaanalysis of prospective studies do support an inverse association between total fibre and cereal fibre intake and risk of type 2 diabetes, with a $9 \%$ and $25 \%$ lower RR per $10 \mathrm{~g} /$ day, respectively, independent of BMI. A stronger inverse association between cereal fibre intake and type 2 diabetes than for fruit or vegetable fibre is consistent with previous meta-analyses of fibre intake and type 2 diabetes [5, 43], and with recent metaanalyses that have shown stronger associations for whole grain intake [44] than for fruit and vegetable intake in relation to risk of type 2 diabetes [45]. Differences in the strength and shape of the dose-response relationship compared with the previous meta-analyses $[5,43]$ may be due to the larger number of studies that was included in the present dose-response analyses and the addition of the EPIC-InterAct data. For
C
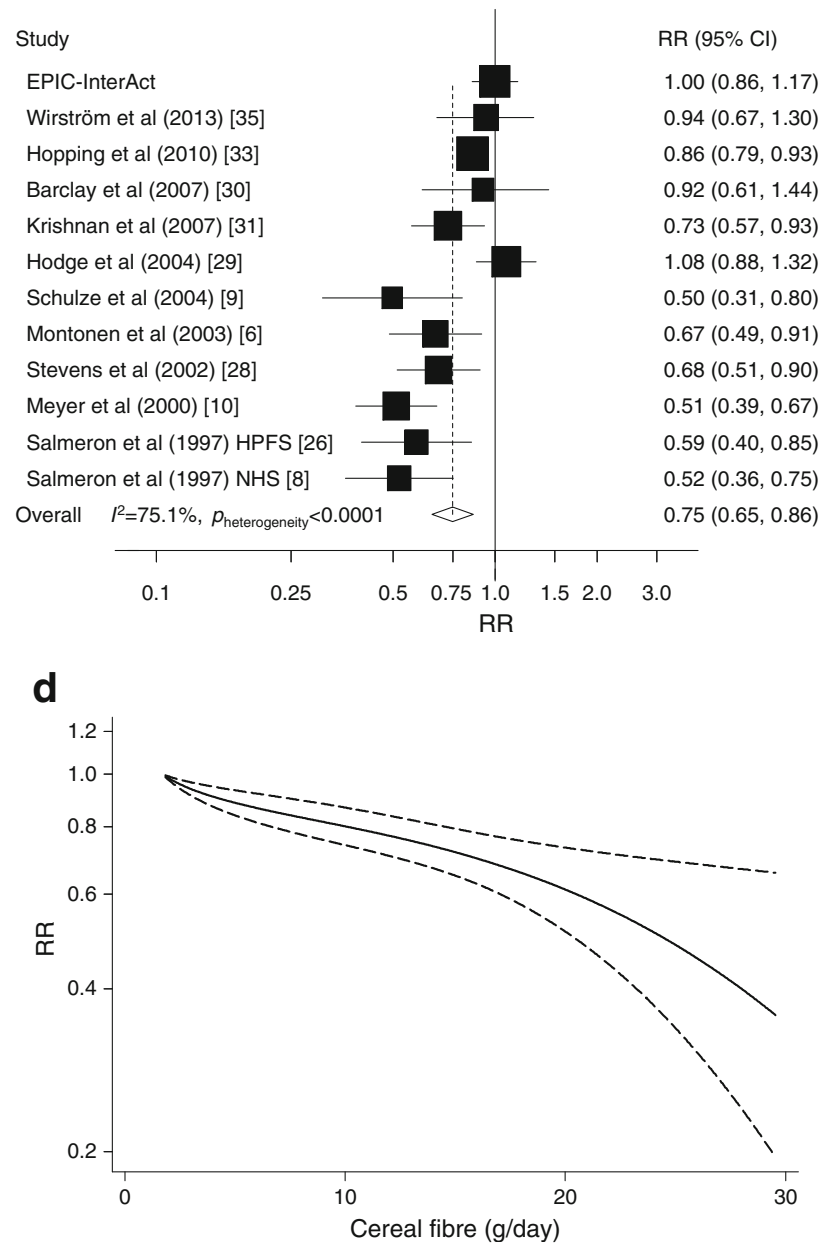

horizontal lines, and the diamond represents the overall estimate and its $95 \%$ CI. The $x$-axis is on a $\log$ scale. In (b) and (d), the solid lines represent the best-fitting fractional polynomial, and the dashed lines represent $95 \%$ CIs

example, in the linear dose-response analysis of dietary fibre, we included seven additional studies $[6-8,26,33,34,39]$ as well as the present EPIC-InterAct study.

It has been suggested that the beneficial effect of cereal fibre observed in many studies could be explained by other nutrients co-ingested with the fibre, for example magnesium and vitamins such as $\mathrm{B}_{1}, \mathrm{C}$ and $\mathrm{E}$ [46]. In the EPIC-InterAct study, adding these nutrients to the models did not materially alter the association with cereal fibre. It is also possible that the low glycaemic index of diets high in total or cereal fibre could explain the relationship between fibre intake and diabetes. A low glycaemic index could lead to a lower postprandial glucose peak, which leads to a decreased insulin demand and protects the pancreas from exhaustion [47]. However, no association was observed between the glycaemic index or glycaemic load and diabetes in the EPIC-InterAct study [48], and further adjustment for both glycaemic index 
a

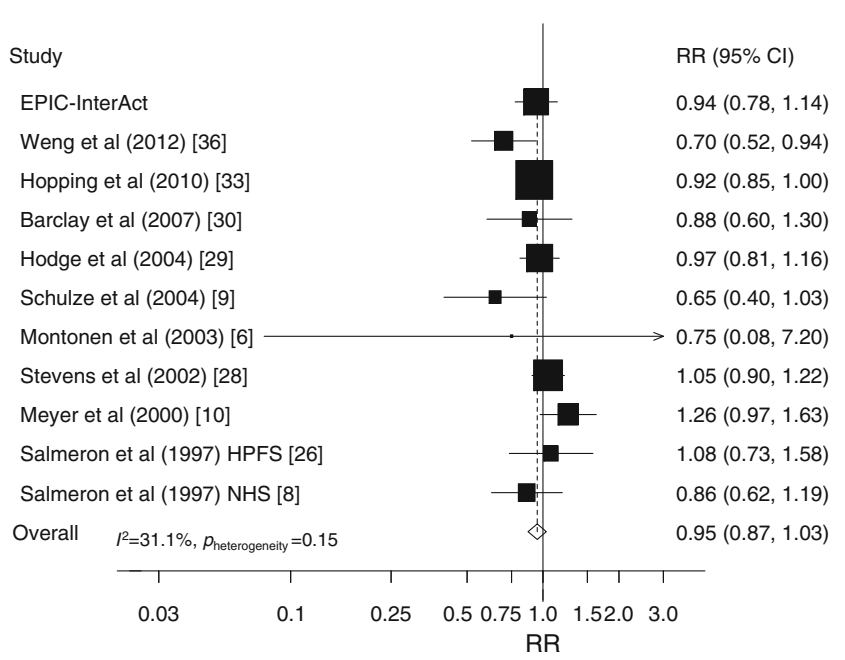

b

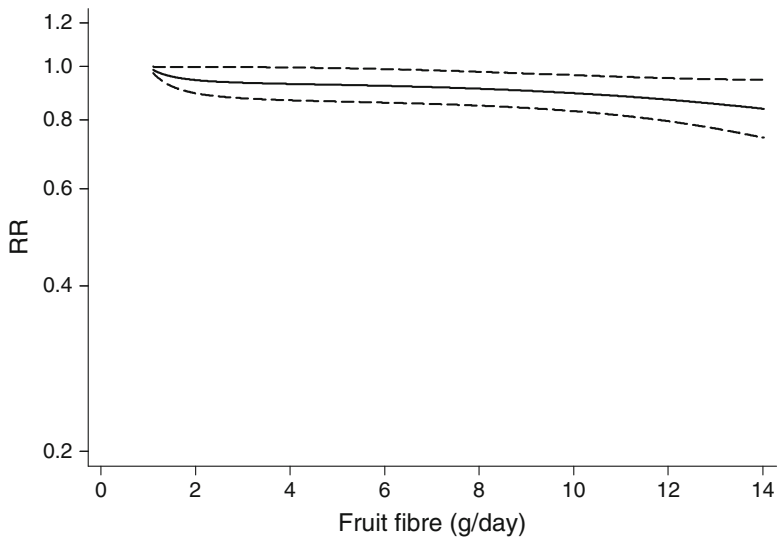

Fig. 3 Fruit fibre (a, b) and vegetable fibre (c, d) and type 2 diabetes, linear dose-response meta-analyses per $10 \mathrm{~g} /$ day $(\mathbf{a}, \mathbf{c})$ and non-linear dose-response meta-analyses (b, d). In (a) and (c), the RR of each study is represented by a square and the size of the square represents the weight of each study to the overall estimate. The $95 \%$ CIs are represented by

and glycaemic load did not change our results. This is consistent with other studies that have found little impact of additional adjustments for glycaemic index, glycaemic load and/or magnesium intake [9, 31, 34]. The intake of fruit fibre was not associated with type 2 diabetes in any of the models, but it is not clear why this is as the range of fruit fibre intake was comparable to that of other studies.

Our study has some limitations that could have affected the results. Measurement error in the assessment of dietary intake by questionnaire may have attenuated an association between fibre intake and type 2 diabetes. Different degrees of measurement error in the assessment of subtypes of fibre intake might explain the different magnitude of association observed with these subtypes. Dietary intake was assessed only at baseline, so we were not able to take into account dietary changes during follow-up. The strengths of the EPIC-InterAct study
C
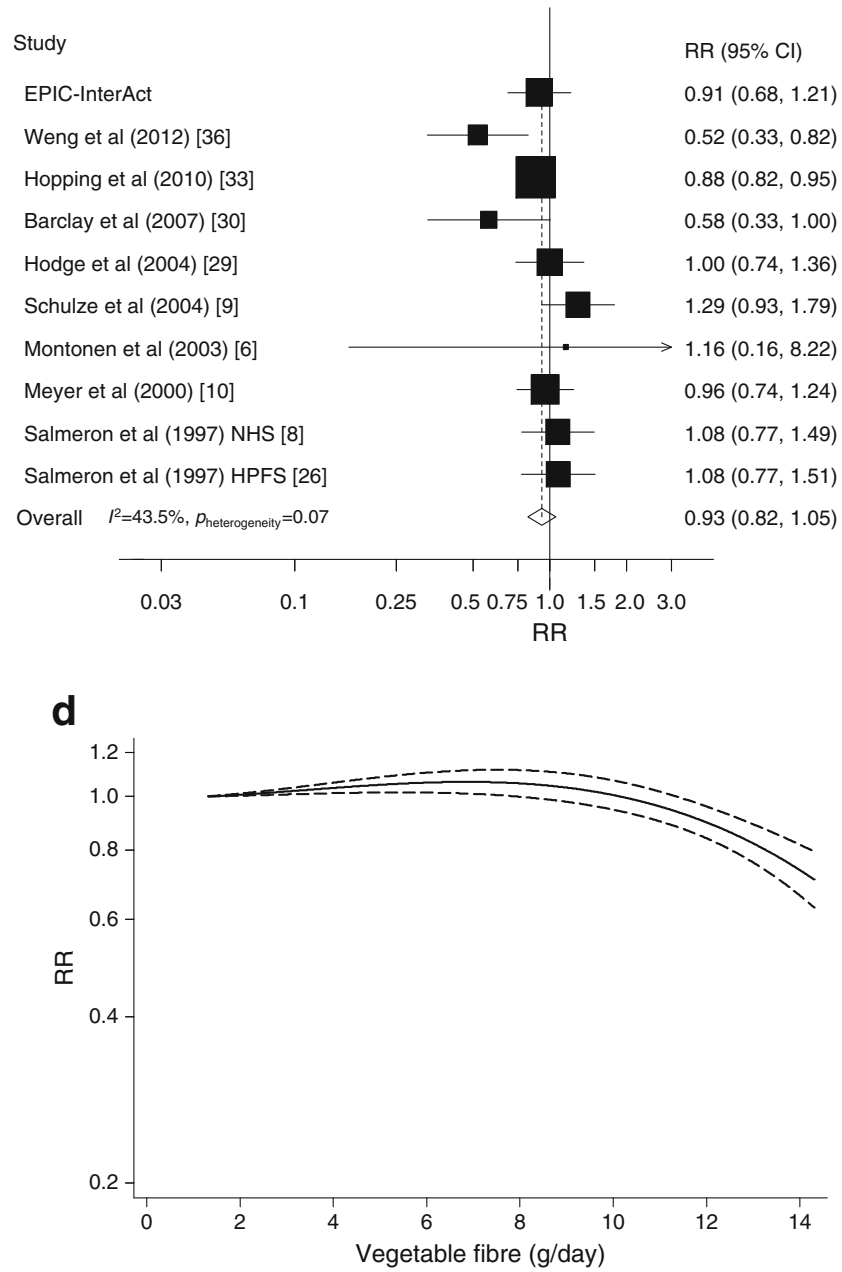

horizontal lines, and the diamond represents the overall estimate and its $95 \%$ CI. The $x$-axis is on a $\log$ scale. In (b) and (d), the solid lines represent the best-fitting fractional polynomial, and the dashed lines represent $95 \%$ CIs

include the prospective design, the large number of cases, the extensive and validated dietary questionnaires, the wide range of dietary fibre intake in eight countries with a large variation in the different sources of fibre intake, and the detailed information on other potential confounders, including height and weight, which were measured in most of the study participants and may have reduced potential confounding by adiposity.

We cannot exclude the possibility that the inverse associations for total fibre and cereal fibre intake in the meta-analysis could be due to residual confounding as fibre intake has been associated with a healthier overall dietary pattern, a lower BMI and higher physical activity $[6,9,10,31]$. Although most studies adjusted for BMI, physical activity, alcohol, smoking and energy intake, relatively few studies adjusted for other dietary factors. However, in the EPIC-InterAct study, adjustment for other dietary factors did not substantially alter the risk 
estimates. It is not clear why our result differs from the result of the meta-analysis. Weight and height were measured (rather than self-reported) in EPIC-InterAct. In general, adjustment for confounding with an imperfect measure of that confounder leads to the possibility of residual confounding. This is possible in this context as some other studies have used more imprecise measures, such as self-reported BMI, and could therefore have more issues with residual confounding. Of 11 studies of cereal fibre that adjusted for BMI, all six studies with self-reported weight and height reported inverse associations [8-10, 26, 31, $33]$, while only two $[6,28]$ out of five of the studies $[6,28,29$, 35] (including EPIC-InterAct) with measured weight and height reported significant inverse associations. However, data for other fibre types and total fibre do not appear to vary by whether weight and height was measured or self-reported, so chance can also not be excluded as an explanation.

In the meta-analysis of cereal fibre, there was some suggestion of small-study bias. However, when the analysis was restricted to studies with a large number of cases $(\geq 1,000)$, there was no evidence of asymmetry in the funnel plot and Egger's test was no longer significant, although the summary estimate was similar to that of the overall analysis.

The attenuation of the inverse associations we observed between total fibre, cereal fibre and vegetable fibre and diabetes after adjustment for BMI in the EPIC-InterAct analysis suggests that the beneficial effect of fibre may be partly mediated by a lower BMI, and this is consistent with other studies $[5,33]$. A previous analysis in the EPIC study found an inverse association between fibre intake, particularly cereal fibre intake, and changes in weight and waist circumference [49], and other studies have also shown an inverse association between fibre intake and overweight, obesity, weight gain or visceral adiposity [50-54], although the data are not convincing [55]. However, as the observed effects of fibre intake on adiposity and weight change are relatively modest, BMI may act as both a confounder and a mediator in the relationship between fibre intake and diabetes. Dietary fibre may affect appetite and energy intake through a range of processes including a delayed emptying rate, a prolonged release of hormonal signals, a slowing of nutrient absorption or altered fermentation in the large intestine $[51,56]$.

Apart from reduced adiposity, dietary fibre may affect the risk of diabetes by other mechanisms as well. Dietary fibre intake improves glycaemic control by decreasing postprandial glycaemia and insulinaemia, and increases insulin sensitivity $[57,58]$. There is also a cross-sectional association between the consumption of high-fibre breakfasts and markers of diabetes risk in children [59]. The fermentation of dietary fibres in the large intestine may alter the growth of specific gut bacteria, affect the production and composition of short-chain fatty acids and thereby affect the secretion of appetite-regulating peptides [60]. Furthermore, fermentable fibres may regulate the uptake of energy from the gut by the production or activation of signalling molecules involved in the host's metabolism, a modification of gut permeability, the release of gut hormones and inflammation [61]. Based on intervention studies, the effect on glycaemic control appears to be stronger for soluble fibre than for insoluble fibre [62, 63], while in the meta-analysis we found an association with insoluble fibre and cereal fibre (which is high in insoluble fibre), but not with soluble fibre. Limited statistical power because of the low number of studies might explain the lack of association for soluble fibre as the risk estimates were of similar size, but further studies are needed to clarify whether there is a difference in the association between soluble and insoluble fibre and risk of diabetes.

In several, but not all, studies [64, 65], dietary fibre, cereal fibre and whole grains have been associated with lower concentrations of inflammatory markers [66-69], serum uric acid [70] and $\gamma$-glutamyltransferase [67, 71], markers that have been associated with increased risk of diabetes [72-74] and higher concentrations of adiponectin [75-77], an adipocyte-secreted cytokine that increases insulin sensitivity and may reduce risk of diabetes [78]. Alternatively, it is possible that other components of foods rich in cereal fibre such as whole grains could contribute to the reduced risk of diabetes by as yet unidentified mechanisms.

In summary, inverse associations were observed between the intake of total, cereal and vegetable fibre and risk of type 2 diabetes in the EPIC-InterAct study, but these associations were no longer significant after adjustment for BMI. In an upto-date meta-analysis of all published prospective studies, we found an inverse association between total fibre and cereal fibre and risk of type 2 diabetes independent of BMI. Taken together, the results indicate that individuals with a diet rich in fibre, especially cereal fibre, may have a lower risk of type 2 diabetes.

Acknowledgements We thank N. Kerrison (MRC Epidemiology Unit, Cambridge, UK) for managing the data for the InterAct Project. We also thank all the EPIC participants and staff for their contribution to the study. We thank D. S. M. Chan (Department of Epidemiology and Biostatistics, School of Public Health, Imperial College, London, UK) for help with extracting data from the Chinese language publication. We are grateful too to D. C. Greenwood (Biostatistics Unit, Centre for Epidemiology and Biostatistics, University of Leeds, UK) for the STATA code used for the non-linear dose-response analysis.

Funding The InterAct project was supported by the European Union (LSHM-CT-2006-037197) in the Framework Programme 6; DA was supported by the Liaison Committee between the Central Norway Regional Health Authority (RHA) and the Norwegian University of Science and Technology (NTNU); TN was supported by the World Cancer Research Fund (WCRF); JWJB and IS were supported by the Netherlands Agency grant IGE05012 and Incentive Grant from the Board of the UMC Utrecht; DLVDA and AMWS were supported by the Dutch Ministry of Public Health, Welfare and Sports (VWS), Netherlands Cancer Registry (NKR), LK Research Funds, Dutch Prevention Funds, Dutch ZON (Zorg Onderzoek Nederland), World Cancer Research Fund (WCRF) and Statistics Netherlands; DP was supported by Associazione Italiana per la Ricerca sul Cancro-AIRC-Italy; TK and AW were supported by the German Cancer Aid, German Cancer Research Center (DKFZ Heidelberg) and German Federal Ministry of Education and Research; PA was supported by the Regional Basque Country Government; GB was 
supported by The Spanish Ministry of Health (ISCIII RETICC RD06/0020/0091) and the Catalan Institute of Oncology; AT and CK were supported by the Danish Cancer Society; MLR was supported by the Government of the Principality of Asturias; SP was supported by Compagnia di San Paolo; PWF was supported by the Swedish Research Council, Novo Nordisk, Swedish Diabetes Association and Swedish Heart-Lung Foundation; OR was supported by the Västerboten County Council; TJK was supported by the Cancer Research UK; NJW, SS, CL and NGF are supported by the Medical Research Council Epidemiology Unit MC UU 12015/1 and MC UU 12015/5.

Contribution statement AK, EJMF and MBS were responsible for the conception of the study. AK and DA analysed the data and wrote the first draft of the manuscript. All authors contributed to the interpretation of the data, revised the article critically for important intellectual content, and approved the final version of the paper to be published. AK and DA are responsible for the integrity of the work as a whole and are the guarantors of this work.

Conflict of interest The authors declare that there is no duality of interest associated with this manuscript.

\section{Appendix}

The InterAct Consortium list of authors is as follows: Anneleen Kuijsten ${ }^{\dagger}$ (Division of Human Nutrition, Wageningen University, Wageningen, the Netherlands); Dagfinn Aune ${ }^{\dagger}$ (Department of Public Health and General Practice, Faculty of Medicine, Norwegian University of Science and Technology, Trondheim, Norway, and Department of Epidemiology and Biostatistics, School of Public Health, Imperial College, London, UK); Matthias B. Schulze (Department of Molecular Epidemiology, German Institute of Human Nutrition Potsdam-Rehbruecke, Nuthetal, Germany); Teresa Norat (Department of Epidemiology and Biostatistics, School of Public Health, Imperial College, London, UK); Geertruida J. van Woudenbergh (Division of Human Nutrition, Wageningen University, Wageningen, the Netherlands); Joline W. J. Beulens (Julius Center for Health Sciences and Primary Care, University Medical Center Utrecht, Utrecht, the Netherlands); Ivonne Sluijs (Julius Center for Health Sciences and Primary Care, University Medical Center Utrecht, Utrecht, the Netherlands); Annemieke M. W. Spijkerman (National Institute for Public Health and the Environment [RIVM], Bilthoven, the Netherlands); Daphne L. van der A (National Institute for Public Health and the Environment [RIVM], Bilthoven, the Netherlands); Domenico Palli (Molecular and Nutritional Epidemiology Unit, Cancer Research and Prevention Institute - ISPO, Florence, Italy); Tilman Kühn (Division of Cancer Epidemiology, German Cancer Research Center [DKFZ], Heidelberg, Germany); Andrea Wendt (Division of Cancer Epidemiology, German Cancer Research Center [DKFZ], Heidelberg, Germany); Brian Buijsse (Department of Epidemiology, German Institute of Human Nutrition
Potsdam-Rehbruecke, Nuthetal, Germany); Heiner Boeing (Department of Epidemiology, German Institute of Human Nutrition Potsdam-Rehbruecke, Nuthetal, Germany); Valeria Pala (Epidemiology and Prevention Unit, Fondazione IRCCS Istituto Nazionale dei Tumori, Milano, Italy); Pilar Amiano (Public Health Division of Gipuzkoa, BioDonostia Research Institute, Health Department of Basque Region, San Sebastian, Spain, and CIBER Epidemiologia y Salud Publica [CIBERESP], Spain, www.ciberesp.es/); Genevieve Buckland (Unit of Nutrition, Environment and Cancer, Cancer Epidemiology Research Programme, Catalan Institute of Oncology [ICO-IDIBELL], Barcelona, Spain); José María Huerta Castaño (CIBERESP, Spain, www. ciberesp.es, and Department of Epidemiology, Murcia Regional Health Council, Murcia, Spain); Anne Tjønneland (Danish Cancer Society Research Center, Copenhagen, Denmark); Cecilie Kyrø (Danish Cancer Society Research Center, Copenhagen, Denmark); Maria Luisa Redondo (Public Health Directorate, Asturias, Spain); Carlotta Sacerdote (Center for Cancer Prevention (CPO-Piemonte), and Human Genetic Foundation [HuGeF], Torino, Italy); María-José Sánchez (Unit of Nutrition, Environment and Cancer, Cancer Epidemiology Research Programme, Catalan Institute of Oncology [ICO-IDIBELL], Barcelona, Spain, and Escuela Andaluza de Salud Pública, Instituto de Investigación Biosanitaria de Granada [Granada.ibs], Granada, Spain); Guy Fagherazzi (Inserm, Center for Research in Epidemiology and Population Health [CESP], U1018, Villejuif, France, and Paris-South University, UMRS 1018, Villejuif, France); Beverley Balkau (Inserm, Center for Research in Epidemiology and Population Health [CESP], U1018, Villejuif, France, and Paris-South University, UMRS 1018, Villejuif, France); Martin Lajous (Inserm, Center for Research in Epidemiology and Population Health [CESP], U1018, Villejuif, France, and Department of Epidemiology, Harvard School of Public Health, Boston, MA, USA, and Center for Research on Population Health, National Institute of Public Health, Cuernavaca, Mexico); Salvatore Panico (Dipartimento de Medicina Clinica e Chirurgia, Federico II University, Naples, Italy); Paul W. Franks (Department of Public Health and Clinical Medicine, Umeå University, Umeå, Sweden, and Department of Clinical Sciences, Lund University, Malmö, Sweden); Olov Rolandsson (Department of Public Health and Clinical Medicine, Umeå University, Umeå, Sweden); Peter Nilsson (Department of Clinical Sciences, Lund University, Malmö, Sweden); Marju OrhoMelander (Department of Clinical Sciences, Lund University, Malmö, Sweden); Kim Overvad (Department of Public Health, Section for Epidemiology, Aarhus University, Denmark); Inge Huybrechts (Dietary Exposure Assessment Group, International Agency for Research on Cancer, Lyon, France); Nadia Slimani (Dietary Exposure Assessment Group, International Agency for Research on Cancer, Lyon, France); 
Rosario Tumino (Cancer Registry and Histopathology Unit, 'Civic - M.P.Arezzo' Hospital, Ragusa, Italy); Aurelio Barricarte (CIBERESP, Spain, www.ciberesp.es/, and Navarre Public Health Institute, Pamplona, Spain); Timothy J. Key (Cancer Epidemiology Unit, Nuffield Department of Population Health, University of Oxford, Oxford, UK); Edith J. M. Feskens (Division of Human Nutrition, Wageningen University, Wageningen, the Netherlands); Claudia Langenberg (MRC Epidemiology Unit, University of Cambridge, School of Clinical Medicine, Institute of Metabolic Science, Cambridge Biomedical Campus, Cambridge, UK); Stephen Sharp (MRC Epidemiology Unit, University of Cambridge, School of Clinical Medicine, Institute of Metabolic Science, Cambridge Biomedical Campus, Cambridge, UK); Nita G. Forouhi (MRC Epidemiology Unit, University of Cambridge, School of Clinical Medicine, Institute of Metabolic Science, Cambridge Biomedical Campus, Cambridge, UK); Elio Riboli (Department of Epidemiology and Biostatistics, School of Public Health, Imperial College, London, UK); Nicholas J. Wareham (MRC Epidemiology Unit, University of Cambridge, School of Clinical Medicine, Institute of Metabolic Science, Cambridge Biomedical Campus, Cambridge, UK).

$\dagger$ Joint first authors.

Open Access This article is distributed under the terms of the Creative Commons Attribution 4.0 International License (http://creativecommons.org/licenses/by/4.0/), which permits unrestricted use, distribution, and reproduction in any medium, provided you give appropriate credit to the original author(s) and the source, provide a link to the Creative Commons license, and indicate if changes were made.

\section{References}

1. Whiting DR, Guariguata L, Weil C, Shaw J (2011) IDF diabetes atlas: global estimates of the prevalence of diabetes for 2011 and 2030. Diabetes Res Clin Pract 94:311-321

2. Seshasai SR, Kaptoge S, Thompson A et al (2011) Diabetes mellitus, fasting glucose, and risk of cause-specific death. N Engl J Med 364:829-841

3. Campbell PT, Newton CC, Patel AV, Jacobs EJ, Gapstur SM (2012) Diabetes and cause-specific mortality in a prospective cohort of one million U.S. adults. Diabetes Care 35:1835-1844

4. Anonymous (2013) Economic costs of diabetes in the U.S. in 2012. Diabetes Care 36:1033-1046

5. Schulze MB, Schulz M, Heidemann C, Schienkiewitz A, Hoffmann $\mathrm{K}$, Boeing H (2007) Fiber and magnesium intake and incidence of type 2 diabetes: a prospective study and meta-analysis. Arch Intern Med 167:956-965

6. Montonen J, Knekt P, Jarvinen R, Aromaa A, Reunanen A (2003) Whole-grain and fiber intake and the incidence of type 2 diabetes. Am J Clin Nutr 77:622-629

7. Lindström J, Peltonen M, Eriksson JG et al (2006) High-fibre, lowfat diet predicts long-term weight loss and decreased type 2 diabetes risk: the Finnish Diabetes Prevention Study. Diabetologia 49: 912-920

8. Salmeron J, Manson JE, Stampfer MJ, Colditz GA, Wing AL, Willett WC (1997) Dietary fiber, glycemic load, and risk of noninsulin-dependent diabetes mellitus in women. JAMA 277:472-477

9. Schulze MB, Liu S, Rimm EB, Manson JE, Willett WC, Hu FB (2004) Glycemic index, glycemic load, and dietary fiber intake and incidence of type 2 diabetes in younger and middle-aged women. Am J Clin Nutr 80:348-356

10. Meyer KA, Kushi LH, Jacobs DR Jr, Slavin J, Sellers TA, Folsom AR (2000) Carbohydrates, dietary fiber, and incident type 2 diabetes in older women. Am J Clin Nutr 71:921-930

11. Kumar V, Sinha AK, Makkar HP, de Boeck G, Becker K (2012) Dietary roles of non-starch polysaccharides in human nutrition: a review. Crit Rev Food Sci Nutr 52:899-935

12. Riboli E, Hunt KJ, Slimani N et al (2002) European Prospective Investigation into Cancer and Nutrition (EPIC): study populations and data collection. Public Health Nutr 5:1113-1124

13. Riboli E, Kaaks R (1997) The EPIC Project: rationale and study design. European Prospective Investigation into Cancer and Nutrition. Int J Epidemiol 26(Suppl 1):S6-S14

14. Langenberg C, Sharp S, Forouhi NG et al (2011) Design and cohort description of the InterAct project: an examination of the interaction of genetic and lifestyle factors on the incidence of type 2 diabetes in the EPIC Study. Diabetologia 54:2272-2282

15. Kroke A, Klipstein-Grobusch K, Voss S et al (1999) Validation of a self-administered food-frequency questionnaire administered in the European Prospective Investigation into Cancer and Nutrition (EPIC) study: comparison of energy, protein, and macronutrient intakes estimated with the doubly labeled water, urinary nitrogen, and repeated 24-h dietary recall methods. Am J Clin Nutr 70:439-447

16. Margetts BM, Pietinen P (1997) European Prospective Investigation into Cancer and Nutrition: validity studies on dietary assessment methods. Int J Epidemiol 26(Suppl 1):S1-S5

17. Slimani N, Deharveng G, Unwin I et al (2007) The EPIC Nutrient Database project (ENDB): a first attempt to standardize nutrient databases across the 10 European countries participating in the EPIC study. Eur J Clin Nutr 61:1037-1056

18. Cust AE, Skilton MR, van Bakel MM et al (2009) Total dietary carbohydrate, sugar, starch and fibre intakes in the European Prospective Investigation into Cancer and Nutrition. Eur J Clin Nutr 63(Suppl 4):S37-S60

19. DeVries JW, Rader JI (2005) Historical perspective as a guide for identifying and developing applicable methods for dietary fiber. J AOAC Int 88:1349-1366

20. Wareham NJ, Jakes RW, Rennie KL et al (2003) Validity and repeatability of a simple index derived from the short physical activity questionnaire used in the European Prospective Investigation into Cancer and Nutrition (EPIC) study. Public Health Nutr 6:407-413

21. The InterAct Consortium (2012) Physical activity reduces the risk of incident type 2 diabetes in general and in abdominally lean and obese men and women: the EPIC-InterAct Study. Diabetologia 55: 1944-1952

22. Willett WC, Howe GR, Kushi LH (1997) Adjustment for total energy intake in epidemiologic studies. Am J Clin Nutr 65: 1220S-1228S

23. Onland-Moret NC, van der A DL, van der Schouw YT et al (2007) Analysis of case-cohort data: a comparison of different methods. $\mathrm{J}$ Clin Epidemiol 60:350-355

24. Riley RD, Higgins JP, Deeks JJ (2011) Interpretation of random effects meta-analyses. BMJ 342:d549

25. Higgins JP, Thompson SG (2002) Quantifying heterogeneity in a meta-analysis. Stat Med 21:1539-1558

26. Salmeron J, Ascherio A, Rimm EB et al (1997) Dietary fiber, glycemic load, and risk of NIDDM in men. Diabetes Care 20:545-550 
27. Hu FB, Manson JE, Stampfer MJ et al (2001) Diet, lifestyle, and the risk of type 2 diabetes mellitus in women. N Engl J Med 345:790-797

28. Stevens J, Ahn K, Juhaeri, Houston D, Steffan L, Couper D (2002) Dietary fiber intake and glycemic index and incidence of diabetes in African-American and white adults: the ARIC study. Diabetes Care 25:1715-1721

29. Hodge AM, English DR, O'Dea K, Giles GG (2004) Glycemic index and dietary fiber and the risk of type 2 diabetes. Diabetes Care 27: 2701-2706

30. Barclay AW, Flood VM, Rochtchina E, Mitchell P, Brand-Miller JC (2007) Glycemic index, dietary fiber, and risk of type 2 diabetes in a cohort of older Australians. Diabetes Care 30:2811-2813

31. Krishnan S, Rosenberg L, Singer M et al (2007) Glycemic index, glycemic load, and cereal fiber intake and risk of type 2 diabetes in US black women. Arch Intern Med 167:2304-2309

32. Wannamethee SG, Whincup PH, Thomas MC, Sattar N (2009) Associations between dietary fiber and inflammation, hepatic function, and risk of type 2 diabetes in older men: potential mechanisms for the benefits of fiber on diabetes risk. Diabetes Care 32:18231825

33. Hopping BN, Erber E, Grandinetti A, Verheus M, Kolonel LN, Maskarinec G (2010) Dietary fiber, magnesium, and glycemic load alter risk of type 2 diabetes in a multiethnic cohort in Hawaii. J Nutr 140:68-74

34. Sakurai M, Nakamura K, Miura K et al (2012) Dietary glycemic index and risk of type 2 diabetes mellitus in middle-aged Japanese men. Metabolism 61:47-55

35. Wirström T, Hilding A, Gu HF, Ostenson CG, Bjorklund A (2013) Consumption of whole grain reduces risk of deteriorating glucose tolerance, including progression to prediabetes. Am J Clin Nutr 97: 179-187

36. Weng LC, Lee NJ, Yeh WT, Ho LT, Pan WH (2012) Lower intake of magnesium and dietary fiber increases the incidence of type 2 diabetes in Taiwanese. J Formos Med Assoc 111:651-659

37. Liu JC, Guo ZR, Hu XS, Zhou ZY, Wu M, Luo WS (2012) Impact of lifestyle and obesity to the risk of type 2 diabetes: a prospective study in Jiangsu province. Zhonghua Yu Fang Yi Xue Za Zhi 46: 311-315

38. Qiao Y, Tinker L, Olendzki BC et al (2014) Racial/ethnic disparities in association between dietary quality and incident diabetes in postmenopausal women in the United States: the Women's Health Initiative 1993-2005. Ethn Health 19:328-347

39. Hodge AM, Dowse GK, Zimmet PZ (1993) Diet does not predict incidence or prevalence of non-insulin-dependent diabetes in Nauruans. Asia Pac J Clin Nutr 2:35-41

40. Greenland S, Longnecker MP (1992) Methods for trend estimation from summarized dose-response data, with applications to metaanalysis. Am J Epidemiol 135:1301-1309

41. Royston P (2000) A strategy for modelling the effect of a continuous covariate in medicine and epidemiology. Stat Med 19: 1831-1847

42. Egger M, Davey SG, Schneider M, Minder C (1997) Bias in metaanalysis detected by a simple, graphical test. BMJ 315:629-634

43. Yao B, Fang H, Xu W et al (2014) Dietary fiber intake and risk of type 2 diabetes: a dose-response analysis of prospective studies. Eur J Epidemiol 29:79-88

44. Aune D, Norat T, Romundstad P, Vatten LJ (2013) Whole grain and refined grain consumption and the risk of type 2 diabetes: a systematic review and dose-response meta-analysis of cohort studies. Eur J Epidemiol 28:845-858

45. Cooper AJ, Forouhi NG, Ye Z et al (2012) Fruit and vegetable intake and type 2 diabetes: EPIC-InterAct prospective study and meta-analysis. Eur J Clin Nutr 66:1082-1092

46. Bakker SJ, Hoogeveen EK, Nijpels G et al (1998) The association of dietary fibres with glucose tolerance is partly explained by concomitant intake of thiamine: the Hoorn Study. Diabetologia 41:1168-1175

47. Dong JY, Zhang L, Zhang YH, Qin LQ (2011) Dietary glycaemic index and glycaemic load in relation to the risk of type 2 diabetes: a meta-analysis of prospective cohort studies. Br J Nutr 106: $1649-1654$

48. Sluijs I, Beulens JW, van der Schouw YT et al (2013) Dietary glycemic index, glycemic load, and digestible carbohydrate intake are not associated with risk of type 2 diabetes in eight European countries. J Nutr 143:93-99

49. Du H, van der A DL, Boshuizen HC et al (2010) Dietary fiber and subsequent changes in body weight and waist circumference in European men and women. Am J Clin Nutr 91:329-336

50. Fogelholm M, Anderssen S, Gunnarsdottir I, Lahti-Koski M (2012) Dietary macronutrients and food consumption as determinants of long-term weight change in adult populations: a systematic literature review. Food Nutr Res doi:10.3402/fnr.v56i0.19103

51. Wanders AJ, van den Borne JJ, de Graaf C (2011) Effects of dietary fibre on subjective appetite, energy intake and body weight: a systematic review of randomized controlled trials. Obes Rev 12: 724-739

52. Koh-Banerjee P, Franz M, Sampson L et al (2004) Changes in whole-grain, bran, and cereal fiber consumption in relation to 8 -y weight gain among men. Am J Clin Nutr 80:1237-1245

53. Liu S, Willett WC, Manson JE, Hu FB, Rosner B, Colditz G (2003) Relation between changes in intakes of dietary fiber and grain products and changes in weight and development of obesity among middle-aged women. Am J Clin Nutr 78:920-927

54. Davis JN, Alexander KE, Ventura EE, Toledo-Corral CM, Goran MI (2009) Inverse relation between dietary fiber intake and visceral adiposity in overweight Latino youth. Am J Clin Nutr 90: 1160-1166

55. Cho SS, Qi L, Fahey GC Jr, Klurfeld DM (2013) Consumption of cereal fiber, mixtures of whole grains and bran, and whole grains and risk reduction in type 2 diabetes, obesity, and cardiovascular disease. Am J Clin Nutr 98:594-619

56. Anderson JW, Baird P, Davis RH Jr et al (2009) Health benefits of dietary fiber. Nutr Rev 67:188-205

57. Weickert MO, Roden M, Isken F et al (2011) Effects of supplemented isoenergetic diets differing in cereal fiber and protein content on insulin sensitivity in overweight humans. Am J Clin Nutr 94:459-471

58. Weickert MO, Pfeiffer AF (2008) Metabolic effects of dietary fiber consumption and prevention of diabetes. J Nutr 138:439-442

59. Donin AS, Nightingale CM, Owen CG et al (2014) Regular breakfast consumption and type 2 diabetes risk markers in 9- to 10-yearold children in the Child Heart and Health Study in England (CHASE): a cross-sectional analysis. PLoS Med 11, e1001703

60. Sleeth ML, Thompson EL, Ford HE, Zac-Varghese SE, Frost G (2010) Free fatty acid receptor 2 and nutrient sensing: a proposed role for fibre, fermentable carbohydrates and short-chain fatty acids in appetite regulation. Nutr Res Rev 23:135-145

61. Diamant M, Blaak EE, de Vos WM (2011) Do nutrient-gutmicrobiota interactions play a role in human obesity, insulin resistance and type 2 diabetes? Obes Rev 12:272-281

62. Jenkins DJ, Wolever TM, Leeds AR et al (1978) Dietary fibres, fibre analogues, and glucose tolerance: importance of viscosity. Br Med J 1:1392-1394

63. Holt S, Heading RC, Carter DC, Prescott LF, Tothill P (1979) Effect of gel fibre on gastric emptying and absorption of glucose and paracetamol. Lancet 1:636-639

64. Tighe P, Duthie G, Vaughan N et al (2010) Effect of increased consumption of whole-grain foods on blood pressure and other cardiovascular risk markers in healthy middle-aged persons: a randomized controlled trial. Am J Clin Nutr 92:733-740 
65. Brownlee IA, Moore C, Chatfield M et al (2010) Markers of cardiovascular risk are not changed by increased whole-grain intake: the WHOLEheart study, a randomised, controlled dietary intervention. Br J Nutr 104:125-134

66. Qi L, van Dam RM, Liu S, Franz M, Mantzoros C, Hu FB (2006) Whole-grain, bran, and cereal fiber intakes and markers of systemic inflammation in diabetic women. Diabetes Care 29:207-211

67. Montonen J, Boeing H, Fritsche A et al (2013) Consumption of red meat and whole-grain bread in relation to biomarkers of obesity, inflammation, glucose metabolism and oxidative stress. Eur J Nutr 52:337-345

68. Ma Y, Griffith JA, Chasan-Taber L et al (2006) Association between dietary fiber and serum C-reactive protein. Am J Clin Nutr 83:760-766

69. Ma Y, Hebert JR, Li W et al (2008) Association between dietary fiber and markers of systemic inflammation in the Women's Health Initiative Observational Study. Nutrition 24:941-949

70. Sun SZ, Flickinger BD, Williamson-Hughes PS, Empie MW (2010) Lack of association between dietary fructose and hyperuricemia risk in adults. Nutr Metab (Lond) 7:16

71. Lee DH, Steffen LM, Jacobs DR Jr (2004) Association between serum gamma-glutamyltransferase and dietary factors: the Coronary Artery Risk Development in Young Adults (CARDIA) Study. Am J Clin Nutr 79:600-605
72. Hu FB, Meigs JB, Li TY, Rifai N, Manson JE (2004) Inflammatory markers and risk of developing type 2 diabetes in women. Diabetes 53:693-700

73. Sluijs I, Beulens JW, van der A DL, Spijkerman AM, Schulze MB, van der Schouw YT (2013) Plasma uric acid is associated with increased risk of type 2 diabetes independent of diet and metabolic risk factors. J Nutr 143:80-85

74. Fraser A, Harris R, Sattar N, Ebrahim S, Davey SG, Lawlor DA (2009) Alanine aminotransferase, gamma-glutamyltransferase, and incident diabetes: the British Women's Heart and Health Study and meta-analysis. Diabetes Care 32:741-750

75. Qi L, Rimm E, Liu S, Rifai N, Hu FB (2005) Dietary glycemic index, glycemic load, cereal fiber, and plasma adiponectin concentration in diabetic men. Diabetes Care 28:1022-1028

76. Qi L, Meigs JB, Liu S, Manson JE, Mantzoros C, Hu FB (2006) Dietary fibers and glycemic load, obesity, and plasma adiponectin levels in women with type 2 diabetes. Diabetes Care 29:1501-1505

77. Cassidy A, Skidmore P, Rimm EB et al (2009) Plasma adiponectin concentrations are associated with body composition and plantbased dietary factors in female twins. J Nutr 139:353-358

78. Li S, Shin HJ, Ding EL, van Dam RM (2009) Adiponectin levels and risk of type 2 diabetes: a systematic review and meta-analysis. JAMA 302:179-188 